УДК 314.1

$10.17213 / 2075-2067-2021-2-149-159$

\title{
ВЛИЯНИЕ ПАНДЕМИИ КОРОНАВИРУСА НА СОЦИАЛЬНО-ДЕМОГРАФИЧЕСКИЙ ПОТЕНЦИАЛ КРЫМСКОЙ МОЛОДЕЖИ
}

\author{
(C) 2021 г. В. А. Чигрин", А. А. Зоткин ${ }^{* *}$, В. В. Узунов" \\ *Крымский филиал Федерального научно-исследовательского \\ социологического центра РАН, г. Симферополь, Россия \\ ** Крымский федеральный университет имени В. И. Вернадского, \\ 2. Симферополь, Россия
}

Целью исследования является анализ влияния последствий пандемии коронавируса на особенности формирования социиально-демографического потенциила крымской молодежи.

Методология исследования. В методологию исследования, результаты которого легли в основу статьи, положены требования классической социологии, предъявляемье как $\kappa$ очному анкетированию (до начала пандемии), так и к онлайн-анкетированию в период самоизоляиии.

Результаты исследования. В статье определены факторы влияния пандемии на планы крымской молодежи относительно создания семей и рождения детей.

Перспективы исследования. В данной публикации даны прогнозы относительно развития сочиально-демографической ситуации на полуострове по окончании пандемии, что позволит органам власти формировать основы демографической политики на ближсайшую перспективу.

Ключевые слова: демографический потенциал; молодежь; брачность; рождаемость; демографическая политика.

\section{IMPACT OF THE CORONAVIRUS PANDEMIC ON THE SOCIO-DEMOGRAPHIC POTENTIAL OF CRIMEAN YOUTH}

\author{
(C) 2021 V. A. Chigrin", A. A. Zotkin"*, V. V. Uzunov* \\ "Crimean Branch of the Federal Research Sociological Center, \\ Russian Academy of Sciences, Simferopol, Russia \\ ${ }^{* *}$ Vernadsky Crimean Federal University, Simferopol, Russia
}

The aim of the study is to analyze the impact of the consequences of the coronavirus pandemic on the peculiarities of the formation of the socio-demographic potential of the Crimean youth.

Research methodology. The methodology of the study, the results of which formed the basis of the article, is based on the requirements of classical sociology, both for face-to-face questioning (before the outbreak of the pandemic) and for online questioning during the period of self-isolation.

The results of the study. The article defines the factors of the impact of the pandemic on the plans of the Crimean youth regarding the creation of families and the birth of children. 
Research prospects. This publication provides forecasts for the development of the sociodemographic situation on the peninsula after the end of the pandemic, which will allow the authorities to form the basis of demographic policy in the near future.

Key words: demographic potential; youth; marriage; birth rate; demographic policy.

Введение. Современные достаточно неоднозначные и противоречивые процессы, которые сопровождают развитие общества, вызывают необходимость изменений в понимании и научной проработке сущности и характера демографических процессов и отношений. Ведь невзирая на особенности процесса глобализации, все активнее охватывающего практически все государства мира, следует констатировать, что именно глобализация дестабилизирует демографическую ситуацию и демографические процессы, которые постоянно вносят коррективы в планы экономической интеграции стран и их объединений, в программы «Открытие границ», «Свободное передвижение» и др. Свою лепту в негативные процессы социально-демографических изменений, происходящих в ряде стран мира, вносит и пандемия коронавируса, вызвавшая ослабление социальных связей и дестабилизацию социального контроля.

Таким образом, следует признать, что демографический фактор продолжает оставаться существенным фактором развития современного общества, который способен влиять (как положительно, так и по большей части негативно) на состояние и характер изменений социума в целом и его составляющих. Тем более, в условиях полиэтнического социума растущее осознание общественной значимости этнического фактора является условием постоянной научной актуальности этой проблематики, которую, по нашему мнению, следует рассматривать на основании универсального подхода, который делал бы возможным согласованное, комплексное использование методов, присущих всем отраслям обществоведения. В качестве оптимального механизма выработки такого подхода мы видим социологический дискурс, в рамках которого подготовлена настоящая статья.

7 мая 2018 года Президент Российской Федерации В.В. Путин подписал Указ, в соот- ветствии с которым до 2024 года страна должна решить ряд стратегических задач «в целях осуществления прорывного научно-технологического и социально-экономического развития Российской Федерации, увеличения численности населения страны, повышения уровня жизни граждан, создания комфортных условий для их проживания, а также условий и возможностей для самореализации и раскрытия таланта каждого человека».

К числу первоочередных задач государственной политики, обозначенных в Указе, относится задача оздоровления демографической ситуации в стране и ее регионах. Отмечено, что правительству Российской Федерации при разработке национальной программы в сфере демографического развития необходимо исходить из того, что к 2024 году необходимо обеспечить увеличение продолжительности здоровой жизни до 67 лет, увеличение суммарного коэффициента рождаемости до 1,7, увеличение доли граждан, ведущих здоровый образ жизни и систематически занимающихся физической культурой и спортом.

Понятно, что эта задача - непростая. Понятно и другое, что основная нагрузка на ее выполнение ложится на конкретные регионы. К их числу, безусловно, относится и Крым, который в социально-демографическом плане довольно сложен.

Так, мы должны понимать, что, во-первых, процесс интеграции Крыма в экономическое, правовое, социально-демографическое, этноконфессиональное пространство России еще не завершился. Специфика Украины, которая в течение длительного времени находилась в пределах искусственно интегрированной в этнонациональном и региональном плане (за счет депортаций и «добровольного переселения») системы прежнего СССР, непосредственно отразилась на всех процессах, происходивших в Крыму. С этим прошлым нам еще предстоит бороться. 
Во-вторых, специфическое физико-географическое положение Крыма, который непосредственно выходит на акватории Черного и Азовского морей, обусловливает особенности занятости и профессиональной принадлежности его населения, тем или иным образом связанного с морскими перевозками, рыболовством, производством и переработкой рыбной продукции, сельским хозяйством и обслуживанием рекреационного комплекса полуострова. С доставшимися от прошлого «перекосами», осложненными разного рода «санкциями», приходится сталкиваться чуть ли не каждый день.

В-третьих, Крым является одним из наиболее населенных регионов, со сложной этнической структурой, несбалансированной системой расселения, сложной и неравномерно развитой социальной инфраструктурой, особенно чувствительной к кризисным явлениям. Это приводит к большому количеству социальных проблем.

Следует учитывать, что крымский социум - это социум, который сформировался на руинах многонациональной империи. Характерными чертами таких империй являются, как правило, ущемления определенных этносов, которые проявлялись в насильственной депортации (не только этнической, но и социальной), наличии поселенческих ограничений (полосы или зоны оседлости, прописка, невозможность получить документы, которые дают возможность переехать в другую местность), создании искусственных этнонациональных территориальных единиц и др.

В социокультурной сфере также можно перечислить множество ограничений языкового характера, ограничений на традиции и обряды, создания таких условий, которые приводили бы к межэтническим конфликтам.

Все эти действия не были присущи «титульной нации СССР», как пытаются доказать некоторые современные политики, в том числе М. Джемилев. Они представляли собой практическое воплощение квазиимперской идеологии, которую насаждали представители руководящих органов КПСС, относившиеся, кстати, к самым разным этносам. Создание в Сибири Еврейской автономии, «добровольное» освоение целинных и залежных земель, массовые депортации и переселения - все это относится не только к «отцу народов», но и к иным адептам «новой исторической общности». Чего стоит только передача Крыма Украине, притом что в Крыму на 1 января 1959 г. фиксировалось 858273 человека, относящих себя к русским. А это, заметьте, 71,43 \% населения Крыма [1].

В результате подобных, крайне субъективных, вмешательств в нормальные этнонациональные и региональные отношения на момент распада советской империи эти отношения были существенно искажены, что и обусловило специфику функционирования современного крымского полиэтнического социума, который еще совсем недавно принадлежал Украине.

Поэтому уже к распаду СССР сложилась особая позиция крымчан по отношению к будущему полуострова. Эта позиция особенно укрепилась к 2004-2005 году, когда Украину потряс первый «помаранчевый майдан», и окончательно укрепилась к 2013-2014 гг.

Для преодоления этих препятствий, без которого решение задач, сформулированных майским указом Президента, становится крайне сложным, нам следует иметь, что называется, «под рукой» данные социологического мониторинга, с помощью которых мы можем понять, что делать, когда делать, где делать и главное - на кого опираться в этом деле.

Даже наши точечные исследования, которые мы осуществляли с московскими исследователями (группа «Циркон»), позволяют отслеживать и прогнозировать некоторые социально-демографические процессы, например, ситуацию с миграциями населения в Крым и из Крыма.

Из таблицы мы видим, что большинство крымчан являются патриотами своего региона, и лишь некоторые хотели бы переехать. Но кто эти «некоторые», в каких районах Крыма они проживают, куда бы они хотели переехать? Ответы на эти вопросы существенно помогли бы в реализации системного подхода к демографической программе Крыма.

Социологи Крыма и Ростова [2] в инициативном порядке попытались изучить некоторые непосредственные процессы на социально-демографическом поле Крыма, изложив полученные данные на Первом Крымском социологическом форуме в конце мая 2018 года. 
Так, было констатировано, что интеграция Республики Крым в общероссийское пространство актуализирует демографическую составляющую развития Республики Крым как движущую интеграционную силу, определяющую количественный и качественный базис человеческого капитала, выступавшего основой пространственного развития данного региона через показатели воспроизводства населения.

Вместе с тем показатели последних лет [3] отчетливо фиксируют негативные черты демографической обстановки в Крыму, связанные со снижением рождаемости, ростом смертности, деформацией половозрастной структуры, увеличением в ней численности пожилого контингента, ростом разводов, несбалансированными миграционными потоками. Именно эти факторы под влиянием системного социально-экономического кризиса определили ведущие тренды в социодемографических процессах 80-90-х гг. и детерминируют турбулентное состояние демографической ситуации в Крыму на современном этапе, что негативно сказывается на социальной консолидации крымского регионального сообщества и его интеграции в общероссийское пространство.

Основные публикации последних лет в области демографического развития Крыма связаны с осмыслением неблагополучной динамики демографических процессов в данном регионе в их связи с самым широким спектром проблем регионального развития: в социально-экономической, политической, социокультурной сферах жизнедеятельности крымского регионального сообщества. Это исследования таких авторов, как М.М. Куз- нецов, Н.А. Сидоренко, И.А. Сухарева, О.С. Третьякова, А. Г. Черникова $[4,5,6,7]$.

В ряде исследований поднимаются проблемы расселения в Республике Крым, что вызвано влиянием миграционных процессов и изменения в половозрастной структуре и этнической структуре населенных пунктов данной республики (А.П. Кучеров, Л.И. Супрычева, В.И. Засухина, Д.И. Узнародов) $[8,9]$.

В работах общероссийского характера демографическая ситуация анализируется также с кризисных позиций, что актуализирует в контексте проблемы интеграции крымского регионального сообщества в общероссийское пространство проблему поиска источников демографического неблагополучия в Крыму и в остальных регионах России с целью их устранения, но в рамках общей концепции пространственного развития России, которая обеспечила бы траекторию движения и устранения кризисных факторов в демографической сфере и ее дальнейшее развитие в русле единой стратегии.

Ученые недаром обращают внимание на то, что недавнее возвращение в состав России Крыма с Севастополем свидетельствует о важности изучения и прогнозирования демографической ситуации, характера расселения, специфики национального и языкового состава и связанных с ними этнокультурных и геополитических проблем в приграничных регионах постсоветского пространства $[10,11]$. Эта проблема актуализируется тем сильнее, чем значительнее масштаб демографических проблем в общероссийском пространстве страны, связываемых многими исследователями с трансформацией института семьи и ее демографического поведения.

Таблица 1

Если бы представилась такая возможность, хотели бы Вы переехать в другой населенный пункт Республики Крым, другой регион, в другую страну? (в \%)

\begin{tabular}{|l|c|}
\hline \multicolumn{1}{|c|}{ Суждения респондентов исследования } & Процент ответов \\
\hline Нет, не хотел бы никуда уезжать & 74,8 \\
\hline Хотел бы переехать в другой населенный пункт в пределах региона & 4,4 \\
\hline Хотел бы переехать в другой регион России & 8,4 \\
\hline Хотел бы уехать за границу, в другую страну & 8,8 \\
\hline Затрудняюсь ответить & 3,6 \\
\hline
\end{tabular}


В целом, если проанализировать сложившиеся направления и точки зрения в области исследования демографических процессов в Крыму, можно выделить в качестве наиболее устоявшихся позиций те, в которых указывается на:

- кризисные факторы в функционировании демографической сферы крымского социума, связанные со снижением рождаемости, ростом смертности, деформацией структуры территориальных поселений (половозрастной, этнической);

- факторы снижения качества населения с точки зрения уровня его физического и духовного здоровья (роста заболеваемости, смертности, снижения репродуктивного потенциала, увеличения числа разводов в семьях);

— трансформацию этнокультурной и социальной структуры региона в контексте влияния миграционных процессов и характера взаимодействия двух основных «этнических акторов» - русских и крымских татар.

В целом можно заключить, что характер демографических проблем, с которыми сталкивается крымское региональное сообщество, во многом идентичен общероссийской демографической ситуации, что определяет значимость широкого спектра теоретических и прикладных работ в этом направлении. Однако прослеживается явный недостаток исследований, раскрывающих специфику демографического развития Крыма в совокупности комплекса влияющих на данный процесс факторов, особенно работ, рассматривающих демографические проблемы развития Крыма в контексте социальных последствий пандемии коронавируса.

Некоторые процессы, наметившиеся в этих условиях в демографической картине региона, прослеживаются в результатах исследований, проведенных социологами Крыма. Здесь мы представляем результаты опроса молодежи Крыма (Республика Крым и г. Севастополь), который был проведен методом простой случайной выборки в апреле-мае 2020 г. (руководитель проекта - А.А. Зоткин, главный научный консультант проекта - В.А. Чигрин, организаторы опроса - Крымский филиал Федерального научно-исследовательского социологического центра РАН и Крымский федеральный университет имени В.И. Вер- надского). Объем выборки составил 1034 респондента в возрасте 18-35 лет по всем регионам Крыма (включая г. Севастополь). Выборка репрезентирует молодежь Крыма по основным социально-демографическим показателям. Ошибка выборки $\approx 3 \%$.

Наиболее наглядными из числа множества индикаторов, характеризующих состояние демографической ситуации в стране или регионе, являются показатели жизненного планирования. Связь очевидна - чем короче планирование, тем ниже уверенность, тем более проблематичной во всех отношениях становится демографическая ситуация.

Отметим, что кризисное состояние в целом характерно для обществ постсоветского пространства. В сознании молодежи оно может иметь особенно острое восприятие. Из таблицы 2 наглядно видно, что значительный сегмент крымской молодежи или вообще не составляет жизненные планы $(15,5 \%)$, или имеет предельно краткие (на 1-7 дней - 18,8\%) и краткие (на 1 месяц - 12,3\%) сроки планирования своей жизни во всех ее сегментах — от места будущей работы до создания семьи и рождения детей. Суммарно сегмент не планирующих или кратко планирующих свою жизнь молодых респондентов составляет чуть более $46 \%$ от опрошенных. Среднесрочное планирование (на полгода и на 1 год) - у 27,5\% респондентов. О долгосрочном жизненном планировании (на 5 и на 10 лет) ответили лишь $15,7 \%$ респондентов. Таким образом, можно предположить, что эта тенденция характеризует некоторый рост неуверенности, что характерно для молодежи, которая находится в поиске своего места в социальном мире и неожиданно столкнулась с пандемией, дестабилизировавшей рынок труда, социальные связи и контакты и т.д.

Социально-экономическая нестабильность, порожденная обострением проблем на мировом уровне, катализатором которых стала пандемия COVID-19, оказывает негативное влияние на социально-психологические установки планирования, в том числе и относительно таких важных жизненных вопросов, как брак и рождение детей (таблица 3).

Из таблицы видно, что значительный сегмент респондентов (20\%) не имеет определенных планов относительно своего бра- 
ка, а традиционная ранее модель заключения брака до 20 лет поддерживается крайне малой частью современной молодежи $(3,6 \%)$. В целом замечено, что модель брачного поведения по сравнению с предыдущими поколениями постепенно смещается в сторону более позднего брака. Вместе с тем это может быть проявлением тенденций культурной глобали- зации и «калькированием» вестернизированных моделей брачного поведения.

Высокий уровень согласия вступить в брак с представителями иных социальных групп (см. табл. 4) демонстрирует, что современная молодежь в целом очень открыта внешнему миру и лишена предрассудков ксенофобии. Относительно меньший уровень со-

Таблица 2

На какой период Вы планируете свою жизнь?, \%

\begin{tabular}{|l|c|}
\hline \multicolumn{1}{|c|}{ Суждения респондентов исследования } & Процент ответов \\
\hline На 1-7 дней & 18,8 \\
\hline На 1 месяц & 12,3 \\
\hline На полгода & 12,1 \\
\hline На 1 год & 15,4 \\
\hline На 5 лет & 10,1 \\
\hline На 10 лет & 5,6 \\
\hline Я вообще не планирую свою жизнь & 15,5 \\
\hline Затрудняюсь ответить & 10,3 \\
\hline
\end{tabular}

В каком возрасте Вы планируете вступить в брак?

Таблица 3

Если Вы в браке, то в каком возрасте вступили?, \%

\begin{tabular}{|l|c|}
\hline \multicolumn{1}{|c|}{ Суждения респондентов исследования } & Процент ответов \\
\hline До 20 лет & 3,6 \\
\hline $20-25$ лет & 37,7 \\
\hline $25-30$ лет & 31,2 \\
\hline $30-35$ лет & 5,9 \\
\hline После 35 лет & 1,5 \\
\hline Не имею определенных планов & 20 \\
\hline
\end{tabular}

Согласие вступить в брак с представителями групп, \%

Таблица 4

\begin{tabular}{|l|c|}
\hline \multicolumn{1}{|c|}{ Суждения респондентов исследования } & Процент ответов \\
\hline С представителем другого вероисповедания & 49,5 \\
\hline С представителем иной расы & 51,8 \\
\hline С представителем иных политических убеждений & 61,2 \\
\hline С представителем иного социального статуса (ниже Вашего) & 67,5 \\
\hline С представителем иной национальности & 68,3 \\
\hline С представителем иной страны & 82,3 \\
\hline С представителем иного социального статуса (выше Вашего) & 84,2 \\
\hline
\end{tabular}


гласия на брак с представителями иной расы $(51,2 \%)$ и иного вероисповедания (49,5\%), скорее, связаны с опасениями трудностей культурной интеграции, в то время как более высокий уровень согласия на брак с представителями более высоких статусов и иностранцами, возможно, имеет подоплеку в социальных мифах, которые бытуют в среде современной молодежи. Заметим, что наиболее консервативными в этом плане являются молодые люди и девушки, исповедующие ислам, а наиболее свободно высказывают свои желания респонденты, не подчеркивающие своей религиозности.

Значительный сегмент крымской молодежи тяготеет, как демонстрируют данные таблицы 5, к модели генеративного поведения с нулевым приростом (в планах родить 2 детей почти у $45 \%$ опрошенных). Модель генеративного поведения с положительным воспроизводством (3 и более детей) зафиксирована у $20,6 \%$ респондентов. Минусовое воспроизводство обозначено в планах почти $22 \%$ тех респондентов, которые хотят завести 1 ребенка (15\%) или вообще не хотят детей $(6,9 \%)$. При этом следует подчеркнуть, что в определении этих тенденций необходимо учитывать подвижность и изменчивость социально-психологических установок молодежи. Здесь мы получили возможность сравнить «доковидные» и «ковидные» показатели, которые показывают, что пандемия

Сколько всего детей Вы хотели бы иметь в будущем?, \%

Таблица 5

\begin{tabular}{|l|c|c|}
\hline \multicolumn{1}{|c|}{ Суждения респондентов исследований } & 2018 год & 2020 год \\
\hline Одного & 8,3 & 15 \\
\hline Двух & 53,4 & 44,9 \\
\hline Трех & 15 & 16,2 \\
\hline Более трех & 5,2 & 4,4 \\
\hline Ни одного & 6,1 & 6,9 \\
\hline Затрудняюсь с ответом & 12 & 12,7 \\
\hline
\end{tabular}

Таблица 6

Что может помешать Вам завести столько детей, сколько хотелось бы?, \%1

\begin{tabular}{|l|c|c|}
\hline \multicolumn{1}{|c|}{ Суждения респондентов исследований } & $\begin{array}{c}2018 \\
\text { год }\end{array}$ & $\begin{array}{c}2020 \\
\text { год }\end{array}$ \\
\hline По состоянию здоровья & 21 & 21,9 \\
\hline У меня есть личные убеждения (религиозные, чайлдфри и т.п.) & 8,3 & 9,4 \\
\hline Это слишком высокий уровень ответственности для меня & 14,7 & 24,6 \\
\hline Материально-экономические трудности & 41,9 & 42,9 \\
\hline Отсутствие помощи со стороны моих родителей и родителей супруга(и) & 2,2 & 3,8 \\
\hline Перспективы (необходимость) профессионального и карьерного роста & 23,9 & 25,8 \\
\hline Отсутствие собственного жилья & 26 & 30,8 \\
\hline Отсутствие любви и взаимопонимания с супругом(ой) & 11,7 & 20,4 \\
\hline Ничто не сможет помешать & 18,5 & 21,8 \\
\hline Затрудняюсь ответить & 11,9 & 8,4 \\
\hline Другое & & 2 \\
\hline
\end{tabular}

1 Процент ответов превышает 100\%, поскольку можно было выбрать несколько вариантов ответа. 
несколько умерила соответствующие планы молодых людей в Крыму.

Подобную тенденцию мы наблюдаем и среди факторов, которые стали бы препятствием в реализации планов по рождению детей, в установках современной молодежи. Как видно из таблицы 6, три лидирующих позиции в 2020 «пандемическом году» занимают материально-экономические трудности (42,9\%), жилищный вопрос (30,8\%), перспективы карьеры $(25,8 \%)$. Немаловажное значение для планов деторождения, с точки зрения молодежи, имеют вопросы здоровья (21,9\%) и психологического климата в отношениях с партнером (так, отсутствие любви и взаимопонимания может стать препятствием для планов деторождения у 20,4\% респондентов). Также заметный сегмент опрошенных $(24,6 \%)$ отметил наличие страхов за высокий уровень ответственности при рождении детей. Логика таких ответов вполне понятна, исходя из общей социальной неуверенности молодежи, о чем уже говорилось выше. В то же время ответы продемонстрировали наличие среди молодежи сегмента, который предельно уверен в своих планах относительно вопроса рождения детей. Ответили, что ничто не сможет им помешать завести столько детей, сколько хотелось бы, 21,8\%. Сугубо эгоистичные установки (личные убеждения, чайлдфри - 9,4\%) в молодежной среде выражены очень слабо, а инфантильно-потребительские (отсутствие помощи со стороны родителей - 3,8\%) практически на самом низком уровне.

Таким образом, кризисное состояние, характерное в целом для обществ постсоветского пространства и обостренное пандемией COVID-19 и ее социально-экономическими последствиями, создает у молодежи, которая переживает это особенно остро, фон некоторой неуверенности в будущем. На это накладываются тенденции глобализации культуры и трансляции вестернизированных моделей социального поведения. Это в совокупности выражается в показателях готовности перехода молодежи к тем или иным моделям брачного и генеративного поведения. При этом следует отметить, что на региональном уровне молодежь все еще имеет запас прочности традиционных семейных ценностей, стимулирующих к выверенным моделям социального поведения в этой сфере.
Заключение. С учетом актуализации вопросов, связанных со стратегией пространственного развития России, осложняющегося социальными последствиями пандемии коронавируса, авторы считают необходимым перенос центра тяжести исследований на региональный уровень.

Так, сегодня необходим глубокий анализ демографической ситуации в Крыму с целью выявления демографического потенциала региона и перспектив его развития в контексте социальной консолидации регионального сообщества. Ибо только консолидированное сообщество может не только эффективно включиться в макропространство, но и стать источником благополучного сценария его развития на основе понимания общих целей и задач пространственного развития и видения конечного результата.

Выступая в Ялте 23 ноября 2018 года, В.В. Путин отметил: «Конкретных результатов мы с вами должны добиваться не на бумаге, а на территориях - в городах и деревнях. Нам нужна не средняя температура по больнице, а реальные изменения. Нам нужны не формулировки красивые на бумаге, а подъем уровня жизни людей».

\section{Литература}

1. Население Крыма [Электронный ресурс]. - Режим доступа: https://ru.wikipedia. org/wiki/.

2. Верещзагина А.В. Демографические индикаторы развития Крыма и его интеграции в Общероссийское пространство / А. В. Верещагина // Состояние и проблемы социокультурной интеграции Крыма в Россию: материалы I Крымского социологического форума (Симферополь, 27-29 мая 2018 г.) / отв. ред. Ю.Г. Волков, В.А. Чигрин; сост. В.О. Вагина, Н.Н. Гонтаренко. - Симферополь, 2018. - Ч. 1. - С. 98-102.

3. Федеральная служба государственной статистики Республики Крым [Электронный ресурс]. - Режим доступа: http://crimea. gks.ru/wps/wcm/connect/rosstat_ts/crimea/ru/ statistics/stat_Cri mea/population/.

4. Кузнецов М.М. Демографический аспект формирования человеческого капитала Республики Крым / М.М. Кузнецов // Общество: политика, экономика, право. - 2015. №6. - C. 30-37. 
5. Сидоренко Н. А. Роль миграции населения в социально-демографическом развитии Крыма второй половины XX века / Н. А. Сидоренко // Молодой ученый. - 2014. №14. - C. 229-233.

6. Сухарева И. А. Сравнительная характеристика заболеваемости, смертности и ожидаемой продолжительности жизни мужчин и женщин в Республике Крым / И.А. Сухарева // Медицинский альманах. - 2016. №1 (41). - C. 14-15.

7. Черникова А.Г. Влияние крымского кризиса на уровень и качество жизни населения [Электронный ресурс] / А. Г. Черникова // Вестник Адыгейского государственного университета. Серия: Экономика. - Майкоп, 2014. — №1 (138). — Режим доступа: https:// cyberleninka.ru/article/n/vliyaniekrymskogokrizisa-na-uroven-i-kachestvo-zhizninaseleniya.

8. Кучеров А.П., Супрычева Л.И., Засухина В.И. Типологизация сельских населенных пунктов Республики Крым по численности постоянного населения / А. П. Кучеров, Л.И. Супрычева, В.И. Засухина // Крымский научный вестник. - 2015. №6. - С. 169-180.

9. Узнародов Д. И. Этносоциальные процессы в Крыму в постсоветский период: конфликтогенные факторы и исторические предпосылки / Д.И. Узнародов // Известия вузов. Северо-Кавказский регион. Серия: Общественные науки. - Ростов-на-Дону, 2016. №3 (191). - С. 60-66.

10. Чигрин B.A. Особенности интеграции этносов Крыма в российский полиэтнический социум / В.А. Чигрин // Гуманитарий Юга России. - 2016. - №4. - С. 84-94.

11. Демографическое развитие постсоветского пространства: сборник статей и аналитических материалов / под ред. М.Б. Денисенко, Р. В. Дмитриева, В. В. Елизарова. М.: Изд-во эконом. ф-та МГУ им. М.В. Ломоносова, 2018. - 368 с.

\section{References}

1. Naselenie Kryma [The population of the Crimea] [Jelektronnyj resurs]. — URL: https:// ru.wikipedia.org/wiki/.

2. Vereshhagina A.V. Demograficheskie indikatory razvitija Kryma i ego integracii v
Obshherossijskoe prostranstvo [Demographic indicators of the development of the Crimea and its integration into the All-Russian space]/ A.V. Vereshhagina // Sostojanie i problemy sociokul'turnoj integracii Kryma v Rossiju: materialy I Krymskogo sociologicheskogo foruma (Simferopol', 27-29 maja 2018 g.) [The state and problems of the socio-cultural integration of the Crimea into Russia: materials of the I Crimean Sociological Forum (Simferopol, May 27-29, 2018)] / in Ju. G. Volkov, V.A. Chigrin (eds.); sost. V. O. Vagina, N. N. Gontarenko. - Simferopol', 2018. - Part 1. - Pp. 98-102.

3. Federal'naja sluzhba gosudarstvennoj statistiki Respubliki Krym [Federal State Statistics Service of the Republic of Crimea] [Jelektronnyj resurs]. — URL: http://crimea.gks.ru/wps/wcm/ connect/rosstat_ts/crimea/ru/statistics/stat_Cri mea/population/.

4. Kuznecov M.M. Demograficheskij aspekt formirovanija chelovecheskogo kapitala Respubliki Krym [Demographic aspects of human capital formation of the Republic of Crimea] / M.M. Kuznecov // Obshhestvo: politika, jekonomika, pravo [Society: politics, economics, law]. - 2015. - №6. - Pp. 30-37.

5. Sidorenko N.A. Rol' migracii naselenija $\mathrm{v}$ social'no-demograficheskom razvitii Kryma vtoroj poloviny XX veka [The Role of migration in the socio-demographic development of the Crimea in the second half of the twentieth century] / N.A. Sidorenko // Molodoj uchenyj [Young scientist]. - 2014. — №14. - Pp. 229-233.

6. Suhareva I.A. Sravnitel'naja harakteristika zabolevaemosti, smertnosti i ozhidaemoj prodolzhitel'nosti zhizni muzhchin i zhenshhin v Respublike Krym [Comparative characteristics of morbidity, mortality and life expectancy of men and women in the Republic of Crimea] / I.A. Suhareva // Medicinskij al'manah [Medical almanac]. - 2016. — №1 (41). — Pp. 14-15.

7. ChernikovaA.G. Vlijanie krymskogo krizisa na uroven' i kachestvo zhizni naselenija [Influence of the Crimean crisis on the level and quality of life of the population] [Jelektronnyj resurs] / A.G. Chernikova // Vestnik Adygejskogo gosudarstvennogo universiteta. Serija: Jekonomika [Bulletin of the Adygeya State University. Series: Economics]. - Majkop, 2014. — №1 (138). — URL: https://cyberleninka.ru/article/n/vliyaniekrymskogo-krizisa-nauroven-i-kachestvo-zhizni-naseleniya. 
8. Kucherov A.P., Suprycheva L.I., Zasuhina V.I. Tipologizacija sel'skih naselennyh punktov Respubliki Krym po chislennosti postojannogo naselenija [Typology of rural settlements of the Republic of Crimea on population]/ A. P. Kucherov, L. I. Suprycheva, V. I. Zasuhina// Krymskij nauchnyj vestnik [Scientific Bulletin of the Crimean]. - 2015. — №6. - Pp. 169-180.

9. Uznarodov D.I. Jetnosocial'nye processy v Krymu v postsovetskij period: konfliktogennye faktory $\mathrm{i}$ istoricheskie predposylki [EthnoSocial processes in the Crimea in the post-Soviet period: conflict-generating factors and historical background] / D. I. Uznarodov // Izvestija vuzov. Severo-Kavkazskij region. Serija: Obshhestvennye nauki [The North Caucasus region. Series:
Social Sciences]. - Rostov-on-Don, 2016. №3 (191). - Pp. 60-66.

10. Chigrin V.A. Osobennosti integracii jetnosov Kryma v rossijskij polijetnicheskij socium [Features of integration of ethnic groups of the Crimea into the Russian polyethnic society]/ V.A. Chigrin // Gumanitarij Juga Rossii. 2016. — №4. - Pp. 84-94.

11. Demograficheskoe razvitie postsovetskogo prostranstva: sbornik statej i analiticheskih materialov [Demographic development of the post-Soviet space: collection of articles and analytical materials] / in M.B. Denisenko, R. V. Dmitriev, V. V. Elizarov (eds.). - Moscow: Izd-vo jekonom. f-ta MGU im. M. V. Lomonosova, 2018. - $368 \mathrm{p}$.

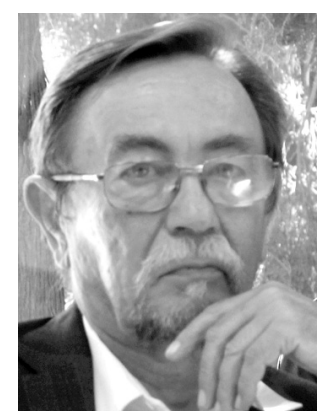

Чигрин Виктор Александрович - доктор социологических наук, профессор, научный руководитель, главный научный сотрудник Крымского филиала Федерального научно-исследовательского социологического центра РАН.

Chigrin Viktor Alexandrovich - Doctor of Sociological Sciences, Professor, Scientific Supervisor, Chief Researcher of the Crimean branch of the Federal Research Sociological Center, Russian Academy of Sciences.

295021, Республика Крым, Симферополь, ул. им. газеты Крымская правда, 4 4 im. gazeta Krymskaya pravda st., 295021, Republic of Crimea, Simferopol, Russia E-mail: sociochigrin@mail.ru 


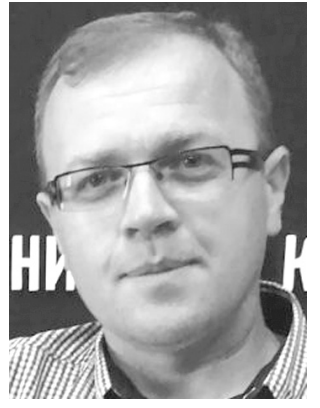

295021, Республика Крым, Симферополь, ул. им. газеты Крымская правда, 4 4 im. gazeta Krymskaya pravda st., 295021, Republic of Crimea, Simferopol, Russia E-mail: zotkin@mail.ru

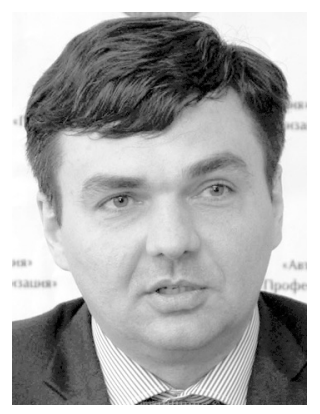

Узунов Владимир Владимирович - доктор политических наук, доцент, директор Крымского филиала Федерального научно-исследовательского социологического центра РАН.

Uzunov Vladimir Vladimirovich - Doctor of Political Sciences, Associate Professor, Director of the Crimean Branch of the Federal Research Sociological Center, Russian Academy of Sciences.

295021, Республика Крым, Симферополь, ул. им. газеты Крымская правда, 4 $4 \mathrm{im}$. gazeta Krymskaya pravda st., 295021, Republic of Crimea, Simferopol, Russia E-mail: vladimir.uzunov@mail.ru 